\title{
Water-Washed Fine and Coarse Recycled Aggregates for Real Scale Concretes Production in Barcelona
}

\author{
Miren Etxeberria ${ }^{1, *(1)}$, Mikhail Konoiko ${ }^{1}$, Carles Garcia ${ }^{1}$ and Miguel Ángel Perez ${ }^{2}$ \\ 1 Department of Civil and Environmental Engineering, Campus Nord, Universitat Politècnica de \\ Catalunya·BarcelonaTECH, 08034 Barcelona, Spain; Mky95@yandex.ru (M.K.); \\ garciauretacarles@gmail.com (C.G.) \\ 2 Hercal Diggers S.L., Ctra de Rubí, 286-B, 08228 Terrassa, Spain; maperez@hercal.es \\ * Correspondence: miren.etxeberria@upc.edu; Tel.: +34-934011788
}

check for updates

Citation: Etxeberria, M.; Konoiko, M.; Garcia, C.; Perez, M.Á. Water-Washed Fine and Coarse Recycled Aggregates for Real Scale Concretes Production in Barcelona. Sustainability 2022, 14, 708. https://doi.org/10.3390/ su14020708

Academic Editor: Jianzhuang Xiao

Received: 15 December 2021

Accepted: 7 January 2022

Published: 9 January 2022

Publisher's Note: MDPI stays neutral with regard to jurisdictional claims in published maps and institutional affiliations.

Copyright: (C) 2022 by the authors. Licensee MDPI, Basel, Switzerland. This article is an open access article distributed under the terms and conditions of the Creative Commons Attribution (CC BY) license (https:// creativecommons.org/licenses/by/ $4.0 /)$.

\begin{abstract}
The use of recycled aggregate to reduce the over-exploitation of raw aggregates is necessary. This study analysed and categorised the properties of water-washed, fine and coarse, recycled aggregates following European Normalization (EN) specification. Because of their adequate properties, zero impurities and chemical soluble salts, plain recycled concrete was produced using $100 \%$ recycled concrete aggregates. Two experimental phases were conducted. Firstly, a laboratory phase, and secondly, an on-site work consisting of a real-scale pavement-base layer. The workability of the produced concretes was validated using two types of admixtures. In addition, the compressive and flexural strength, physical properties, drying shrinkage and depth of penetration of water under pressure validated the concrete design. The authors concluded that the worksite-produced concrete properties were similar to those obtained in the laboratory. Consequently, the laboratory results could be validated for large-scale production. An extended slump value was achieved using $2.5-3 \%$ of a multifunctional admixture plus $1-1.2 \%$ of superplasticiser in concrete production. In addition, all the produced concretes obtained the required a strength of $20 \mathrm{MPa}$. Although the pavement-base was produced using $300 \mathrm{~kg}$ of cement, the concrete made with $270 \mathrm{~kg}$ of cement per $\mathrm{m}^{3}$ and water/cement ratio of 0.53 achieved the best properties with the lowest environmental impact.
\end{abstract}

Keywords: recycled concrete aggregate; recycled aggregate concrete; workability; compressive strength; pavement

\section{Introduction}

In 2018 , construction and demolition waste was $35.4 \%$ of the total waste $(2277$ million tonnes) generated in the European Union (EU) by all economic activities including households, of which only $54.2 \%$ was recovered [1,2]. Consequently, the demolition of concrete structures causes a considerable volume of waste that terminates in landfills. The guidelines of the European Commission [3] are designed to encourage a change in production procedures to embrace a circular, more sustainable and eco-respectful model in which waste is re-introduced into production processes, reducing raw material over-exploitation and maximising material life cycles. Plaza et al. [4] concluded that the benefits of using recycled coarse and fine aggregates to replace natural aggregate partially lie not only in $\mathrm{CO}_{2}$ emissions reduction in concrete manufacture but also in the significant mitigation of the environmental impacts induced by stockpiling the respective waste. Moreover, about $75-80 \%$ of the total concrete components materials are aggregates [5]. Today, the production and use of natural resources such as natural aggregates in concrete production reduce natural resources and increase the volume of atmospheric pollutants [6]. Therefore, recycling waste concrete and concretes from damaged or demolished structures are essential for producing recycled concrete aggregates (RCA), thus mitigating the environmental impacts.

The demand for non-renewable natural resources and industrial products, especially mineral aggregates from quarry extraction, is high for highway construction and main- 
tenance [7]. Therefore, the most widespread practice to achieve pavement sustainability is to lower the quantity of virgin aggregates by partially or fully replacing them with alternative aggregates. In addition, the available literature shows that alternative aggregate, as recycled concrete aggregate, could be effectively used for concrete pavements [8-11]. The mentioned field investigation results indicate that it is possible to produce pavements from recycled aggregates that are equivalent in all aspects to pavements made with conventional aggregates when up to $40 \%$ of coarse RCA are used to replace natural aggregates. Gress et al. [12] described that the pavement produced with up to $25 \%$ of fine recycled concrete aggregates also achieved adequate properties although with a slight increase of shrinkage value with respect to that in concrete produced only employing coarse RCA. Moreover, recycled concrete made with coarse RCA aggregates have been employed in certain, although few, real structural concrete projects [13]. In Hong Kong [14], from 2022 to 2005, the acceptable behaviour of structural concretes grades C20 and C25 were verified, producing concretes with recycled coarse aggregate replacement levels of 100 and $20 \%$, respectively. Zhang and Zhao [15] also proved 50\% coarse RCA in structural concrete production. However, for the structural elements studied by Xiao et al. [16], up to $30 \%$ of coarse RCA were used in concrete production. The use of RCA is still limited. However, as mentioned previously, coarse recycled aggregates (C-RCA) have been proven to be suitable for concrete production [17]. Moreover, their use in concrete production as a structural material has been widely analysed and validated in many applications $[13,18,19]$. However, the use of fine recycled concrete aggregates (F-RCA) is less widespread due to their more negative effect on concrete properties [20].

RCA aggregates have a lower quality than the natural aggregate (NA) because of attached mortar to the stone particles in RCA. In contrast to NA, RCA has the following properties: more water absorption, less bulk density, more abrasion loss and more crushability $[21,22]$. In particular, fine RCA could also have more dust particles, more organic impurities and also harmful chemicals because of earth mixing with concrete after building demolition [23]. Despite these weaknesses, the un-hydrated cement of the original concrete available in the RCA may play a positive role in its use in structural concrete. In addition, in the case of the use RCA, the specific surface of the aggregates improves the binder/recycled aggregate interface [24].

Coarse and fine RCA in concrete production affects workability and hardened-state (mechanical, physical and durability) properties. Recycled aggregate concrete (RAC) is typically associated with lower workability than natural aggregate concrete (NAC) of the same composition [25]. This is attributed to the poor shaping properties of crushed RCA when compared to NA. If there is proper compensation for water absorption, workability is essentially affected by the shape of the aggregates $[26,27]$. The reduction of workability is confirmed with the increased replacement of NA with RCA, especially in the finer fraction [28]. Partial absorption of the superplasticiser by the aggregates also occurs, and increased fines in the content are due to a partial loss of the aggregates' mortar during the mixing process [26]. Tobori et al. [29] found that when superplasticiser is added to RAC mix, instead of acting on the cement grains, the absorption of its liquid phase occurs through F-RCA. Evangelista and de Brito [30] found that polymer chains have a larger contact area with fine recycled aggregates than natural ones. Nedeljkovi'c et al. [27], after an exhausted review analysis, concluded that researchers had offered many reasonable explanations on complex flow behaviour of recycled concretes through a combination of experiments and theories. They described that there is no universal approach to obtain and maintain satisfactory workability of mortars/concretes with F-RCA.

It is generally believed that concrete compressive strength decreases as the amount of recycled concrete replacement increases [31], which may be due to the old mortar in fine RCA that makes concrete more porous and less dense [32]. As a result, the concrete produced with $100 \%$ RCA (coarse plus fine recycled aggregated) obtained a lower compressive strength $[4,27]$. However, the tensile strength can improve due to the improvement of the interface transition zone in concretes containing RCA $[4,10]$. 
According to Zhang et al. [33], both F-RCA and C-RCA significantly influence the drying shrinkage behaviour of concrete. Total (100\%) replacement of natural aggregates with RCA (including both F-RCA and C-RCA) increased the drying shrinkage by more than $100 \%$ (102.0-116.9\%). In addition, a higher water absorption ratio and a lower density RCA resulted in higher shrinkage strains. However, compared with the influence of C-RCA, the effect of F-RCA is relatively lower. In particular, C-RCA with a $100 \%$ replacement ratio increased the drying shrinkage. Sadati and Khayat [9] also determined that the increasing the fine RCA content from 0 to $15 \%$ had no significant effects on drying shrinkage of pavement concrete.

Although recycled concrete produced with 100\% of recycled aggregate achieves a lower strength and a higher shrinkage than those of conventional concretes, the washing of recycled aggregates could guarantee the quality and consequently the durability of the concrete produced. In order to assure RCA aggregate quality, it is imperative to use innovative recovery plants to manage construction and demolition waste efficiently [34].

The recycled aggregates used in this study were obtained from an innovative recycling plant (see Figure 1) located in Barcelona, Spain. Two types of demolition material are treated separately at the plant: concrete waste (more than $95 \%$ is concrete) and mixed waste (with approximately $30 \%$ ceramic material). After crushing these to the desired aggregate size (usually $0 / 20 \mathrm{~mm}$ ), the cleaning and sieving processes of the mixed recycled aggregates (RMA) and RCA are carried out. Fine (F-) and course (C-) fractions are produced separately, making them suitable for concrete production. In this study, the F-RCA and C-RCA were analysed for use in concrete production.

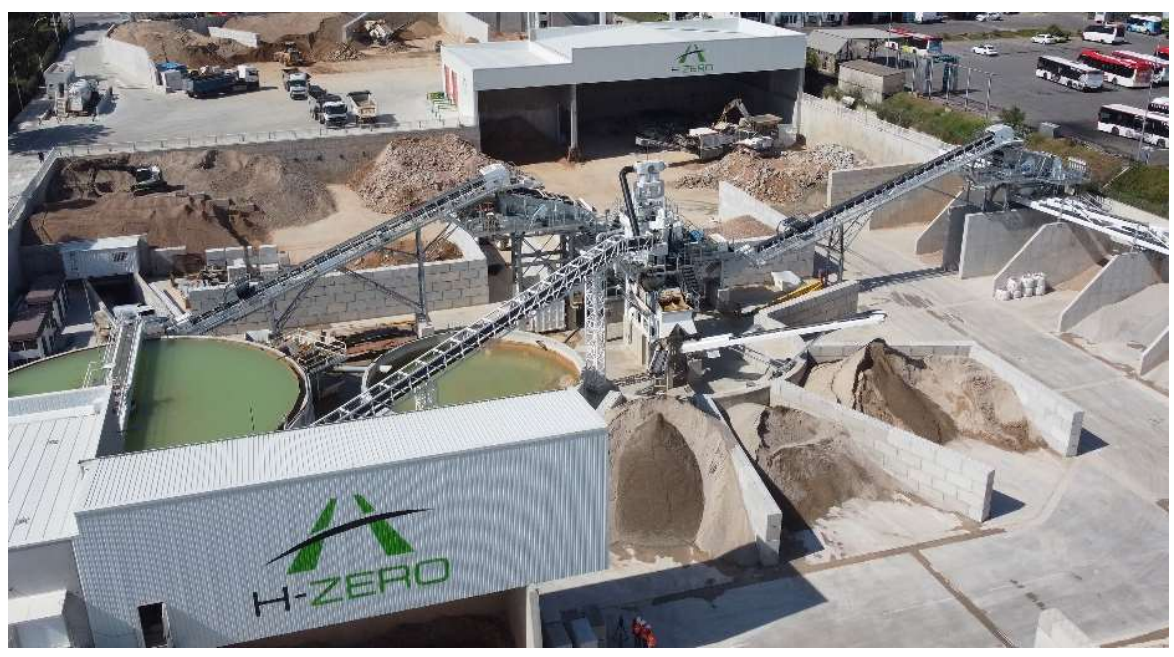

Figure 1. CDW recovery plant to water-washed recycled aggregate [35].

The production of high-quality plain concrete using $100 \%$ water-washed fine and coarse RCA aggregates without employing natural aggregates can be possible if the recycled aggregates fulfil the requirements to be used in concrete production. The objective of this study was to analyse the quality of water-washed C-RCA and F-RCA aggregates produced in the innovative plant and validate them to be used in plain concrete production by building a real pavement-base layer. The production of plain concrete was analysed in two phases: (1) laboratory experiments and (2) on-site pavement-base layer construction. In the first phase, the suitable concrete mix proportions were tested to see if they accomplish the minimum required properties of having an adequate workability $(6-8 \mathrm{~cm}$ of slump test) 30 min after RAC concrete production and a minimum compressive strength of $20 \mathrm{MPa}$ at 28 days of curing. Moreover, other properties such as the flexural strength, physical properties, drying shrinkage and depth of penetration of water under pressure were also validated in the concrete design. The second phase would verify if the worksite-produced concrete achieved adequate properties similar to those obtained in the laboratory. 


\section{Materials and Methods}

\subsection{Materials}

\subsubsection{Cement and Chemical Admixtures}

The cement CEM II A-L 42.5 R (88\% clinker, 12\% limestone, excluding the set regulator, added in 5\%) was used. The composition of the cement is shown in Table 1.

Table 1. Composition of cement as the percentage of total weight.

\begin{tabular}{cccccccccc}
\hline Cement & $\mathbf{S i O}_{2}$ & $\mathbf{C a O}$ & $\mathbf{F e}_{2} \mathbf{O}_{3}$ & $\mathbf{A l}_{2} \mathbf{O}_{3}$ & $\mathbf{M g O}$ & $\mathbf{S O}_{3}$ & $\mathbf{N a}_{2} \mathbf{O}$ & $\mathbf{K}_{2} \mathbf{O}$ & $\mathbf{L O I}$ \\
\hline CEM II A-L 42.5 R & 19.33 & 62.71 & 2.65 & 3.43 & 1.36 & 3.52 & 0.06 & 0.8 & 5.28 \\
\hline
\end{tabular}

Two chemical admixtures were employed for concrete production: a multifunctional admixture $(\mathrm{P})$ and a superplasticiser $(\mathrm{S})$. The mix recommended by the manufacturer for the $S$ was $0.3-2.0 \%$ and $0.5-1.5 \%$ for the $P$ admixtures based on the weight of the cement.

\subsubsection{Recycled Concrete Aggregate Production and Its Properties}

The production of C-RCA and F-RCA aggregates was conducted in an innovative washing recycling plant. Once all the polluted components, big pieces of steel, wood or plastic, are removed from the demolition waste, the clean concrete waste is crushed to $0 / 20 \mathrm{~mm}$ recycled aggregate fractions. At this point, the water-washed treatment process and different aggregate fraction production starts: (1) the $0 / 20 \mathrm{~mm}$ fractions are transported to the recovery plant by conveyor belt for the next steps in the process. The recycled material is passed through a magnetic separator, and under the water spraying process, the $0 / 20 \mathrm{~mm}$ fractions pass through a $4 \mathrm{~mm}$ sieve where the fine and coarse fractions are separated. (2) The recycled aggregate fractions finer than $4 \mathrm{~mm}$ go to the hydro-cyclone separators. At this point, the material is divided into three recycled fraction sizes: $0 / 4 \mathrm{~mm}$, $0 / 2 \mathrm{~mm}$ and a fraction finer than $63 \mu \mathrm{m}$ (filler and clay). (3) After the cleaning process (with water and brushing), the coarse recycled aggregate fractions $(>4 \mathrm{~mm})$ are sieved in three different fractions, $14 / 20 \mathrm{~mm}, 8 / 14 \mathrm{~mm}$ and $4 / 10 \mathrm{~mm}$.

Although the cleaning procedure is conducted via a water system, the entire volume of water employed in the treatment process is reused satisfactorily. In addition, rainwater is also harvested through storage tanks.

Four fractions $(0 / 2 \mathrm{~mm}, 0 / 4 \mathrm{~mm}, 4 / 10$ and $8 / 20)$ of RCA, designated FR1, FR2, CR1 and CR2, respectively, were used for concrete production (see Figure 2). The $8 / 20 \mathrm{~mm}$

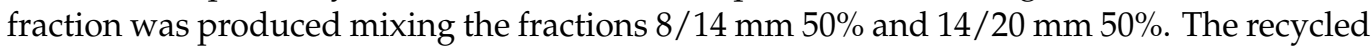
aggregates were characterised following EN 12620 "Aggregates for concrete" specifications.

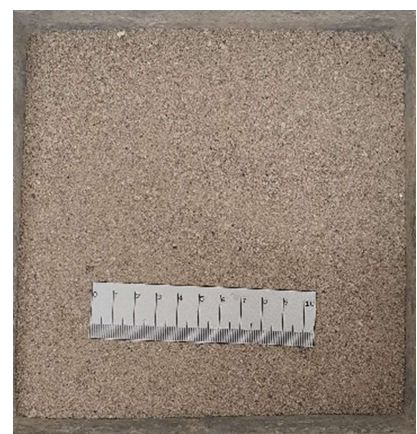

(a) FR1: 0/2 $\mathrm{mm}$

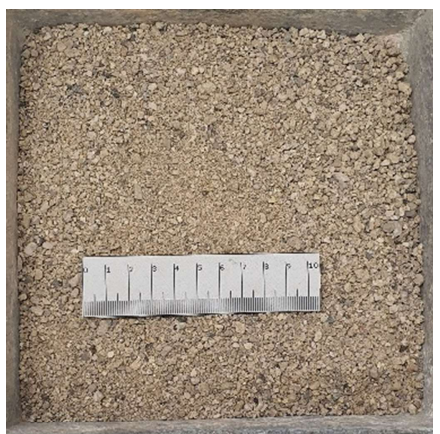

(b) FR2: 0/4 mm

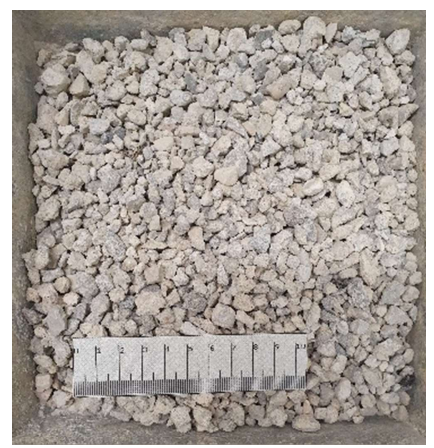

(c) CR1: 4/10 mm

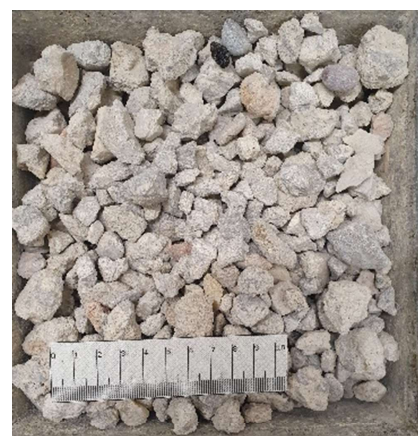

(d) CR2: $8 / 20 \mathrm{~mm}$

Figure 2. The four recycled aggregates (each line in the ruler are $10 \mathrm{~mm}$ ).

The constituents of C-RCA aggregates (CR1 and CR2) were: Rc (Concrete and mortar) $+\mathrm{Ru}$ (unbound aggregate) of $96.27 \%$, Rb (Ceramic) $1.94 \%$, Ra (Asphalt) $1.40 \%$ and X (other impurities) $0.4 \%$, determined following the EN 933-11:2009 specifications. According to 
the EN 12,620 specifications, the RCA aggregates composed of more than $95 \%$ concrete are categorised as Type A (Rc90, Rcu95, Rb10, Ra1, FL2 and XRg1).

The grading distribution of the four fractions of recycled aggregates $0 / 2$ (FR1), 0/4 (FR2), 4/10 (CR1) and 8/20 (CR2) are shown in Figure 3. They were determined following EN 933-1 specification. According to the grading distribution, the fine fractions (FR1 and FR2) were categorised as Gf85. The 4/10 gravel fraction was classified as Gc90/15 and the $8 / 20$ fraction as Gc85/20, the categories being highlighted by the Spanish concrete Structural Code [36].

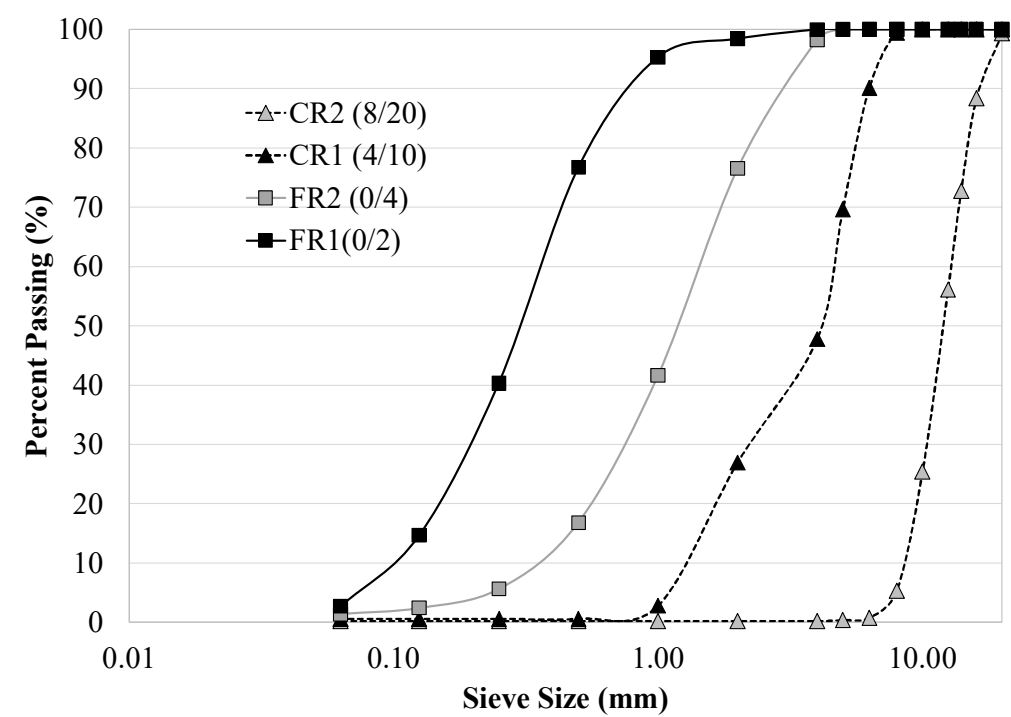

Figure 3. The grading distribution of all the recycled concrete aggregate fractions (FR1, FR2, CR1 and CR2).

The coarse recycled aggregates (CR1 and CR2) contained less than $1.5 \%$ of particles under $63 \mu \mathrm{m}$ classified in the maximum category of $\mathrm{f} 1.5$. In addition, the FR1 and FR2 had a filler quantity of less than $3 \%$. Therefore, they were assigned the top category $\mathrm{f} 3$.

The density and absorption capacity of all the aggregates fractions, described in Table 2, were determined following UNE-EN 1097-6 specification. All recycled aggregates met the requirements of the Structural Code [36] at 7\% (established by the concrete Structural Code). It should be clarified that FR1 $0 / 2$ sand was always mixed with FR2 0/4 sand (using 20\% 0/2 and 80\% 0/4). Therefore, the mixture fraction met the limit set by the structural code of $7 \%$ absorption capacity. Furthermore, as mentioned above, all the used recycled aggregates were found to be well within the absorption limitation established by international regulations for recycled aggregates to be used in non-structural concrete. For example, $10 \%$ in Hong Kong and 20\% in The International Union of Laboratories and Experts in Construction Materials, Systems and Structures (RILEM, Paris, France) German and Norwegian specifications [37].

Table 2. Dry density and absorption capacity of RCA.

\begin{tabular}{cccccccccc}
\hline & FR1-0/2 & Desv & FR2-0/4 & Desv & CR1-4/10 & Desv & CR2-8/20 & Desv \\
\hline Dry Density $\left(\mathrm{kg} / \mathrm{dm}^{3}\right)$ & 2.12 & 0.06 & 2.29 & 0.05 & 2.24 & 0.03 & 2.30 & 0.01 \\
\hline Absorption $(\%)$ & 7.8 & 0.04 & 5.6 & 0.46 & 6.1 & 0.05 & 5.6 & 0.25 \\
\hline
\end{tabular}

The per cent of acid-soluble sulphate and water-soluble chlorides salts were determined according to the EN 1744-1 specification. The limit established by the Structural Code for aggregates used in the manufacture of concrete is $0.8 \%$ and $0.05 \%$ of acid-soluble sulphates and soluble chlorides, respectively. Table 3 summarises the obtained values. All recycled aggregates met the standard requirement. 
Table 3. Chemical analysis of recycled aggregates.

\begin{tabular}{ccccc}
\hline & FR1-0/2 & FR2-0/4 & CR1-4/10 & CR2-8/20 \\
\hline Acid soluble Sulphate (\%) & 0.13 & 0.11 & 0.23 & 0.16 \\
\hline Water-Soluble Chloride salts (\%) & 0.005 & 0.0014 & 0.007 & 0 \\
\hline
\end{tabular}

The shape factor and Los Angeles abrasion coefficient of coarse recycled aggregate fractions were determined following UNE-EN 933-3 and UNE-EN 1097-2 specifications, respectively. The shape factor of the recycled concrete aggregate fraction was $6 \%$, below $35 \%$ (maximum value allowed by the Structural Code). According to the Los Angeles coefficient, RCA obtained a maximum of $36 \%$, less than $40 \%$, a limiting value for structural concrete aggregates. Following the EN 12,620 specification, the shape factor and Los Angeles abrasion coefficient are classified as $\mathrm{Fl}_{15}$ and $\mathrm{LA}_{40}$, respectively.

As mentioned above, the recycled aggregates were water cleansed. Consequently, after the washing process, all RCA aggregate fractions had a high moisture content in oversaturated conditions. Therefore, in order to control de water amount in concrete mixture, the moisture of aggregates was determined before their use in concrete production. Many researchers recommend the employment of recycled aggregates in highly humid conditions to produce concrete. However, it should not be saturated, as this could negatively affect the interface transition zone [38,39]. Nevertheless, in this case, due to the water washing process, the recycled aggregates were employed in wet conditions, sometimes even oversaturated. According to the obtained properties of RCA, the water-washed industrial treatment process guaranteed high quality RCA, adequate to be used in concrete. Other recycled aggregates treatments [40], only applied in laboratory scale, achieved also improvements in their physical properties. However, recycled aggregates which are required to be in a dry state or with medium humidity grade have been found up to be difficult to combine with the industrial water-washed treatment.

\subsection{Methods}

Two phases of concrete production were conducted. Phase 1 included experimental laboratory work. For pavement-based layer construction, adequate mix proportions of concrete with $100 \%$ fine and coarse recycled aggregates (RAC concrete) were designed. The concrete was required to have acceptable workability ( $6-8 \mathrm{~cm}$ of slump test) $30 \mathrm{~min}$ after casting for adequate concrete placement. In addition, the produced concrete should have a minimum of $20 \mathrm{MPa}$ compressive strength (strength in cylindrical specimens defined by Structural Code) after 28 days of curing. In phase 2, a RAC concrete pavement-base layer with a minimum of $20 \mathrm{MPa}$ compressive strength (in cylindrical specimens) was built in Barcelona's city centre using an adequate mix proportion; the fresh and hardened properties were determined.

\subsubsection{Laboratory Work, Phase 1: Mix Proportions and Test Procedure}

All the concretes were produced employing $100 \%$ of fine and coarse RCA. $300 \mathrm{~kg}$, $280 \mathrm{~kg}$ and $270 \mathrm{~kg}$ of cement were used in different mix proportions (see Table 4) to determine the minimum amount of cement needed to achieve adequate properties. In addition, the effective water/cement ratio was defined to establish the concretes' mix proportions. While the effective water/cement ratio 0.55 was defined for the concretes produced with $300 \mathrm{~kg}$ and $285 \mathrm{~kg}$ of cement per $\mathrm{m}^{3}$ of concrete, the value of $0.52-0.53$ was defined for concrete produced with $270 \mathrm{~kg}$ of cement. The day before producing each concrete, all fraction of recycled aggregates were introduced into the oven at $100{ }^{\circ} \mathrm{C}$, and the aggregates humidity was determined to calculate the water amount to be added for concrete production and control its effective water/cement ratio. The average humidity values (and its standard deviation) of the FR1, FR2, CR1 and CR2 recycled aggregates were $12.2 \%(0.7 \%)$, $6.7 \%(0.4 \%), 6.1 \%(1 \%)$ and $4.6 \%(0.8 \%)$, respectively. The fine fractions (FR1 and FR2) were oversaturated when concretes were produced. Consequently, the water present on 
the surface was considered part of effective water for concrete production. However, the coarse recycled aggregates (CR1 and CR2) had a high humidity but were not saturated. In this case, their effective absorption capacity was calculated (determined by submerging them in water for $20 \mathrm{~min}$ ), and the determined water amount was added to the concrete to be absorbed by the CR1 and CR2 in order to maintain a constant effective water/cement ratio [5]. The multifunctional $(\mathrm{P})$ and superplasticiser $(\mathrm{S})$ chemical admixtures were used in different percentages to achieve the desired workability of $6-8 \mathrm{~cm}$ slump value at $30 \mathrm{~min}$ or later after casting.

Table 4. Mix proportions of concrete mixtures. The values are given as weight (in dry condition) over the volume of concrete production $\left(\mathrm{kg} / \mathrm{m}^{3}\right)$.

\begin{tabular}{|c|c|c|c|c|c|c|}
\hline & RAC-300 & RAC-285-1 & RAC-285-2 & RAC-270-1 & RAC-270-2 & RCA-270-3 \\
\hline CEM II A-L 42.5 R & 300 & 285 & 285 & 270 & 270 & 270 \\
\hline Efective $\mathrm{w} / \mathrm{c}$ ratio & 0.55 & 0.55 & 0.55 & 0.52 & 0.52 & 0.53 \\
\hline Total w/c ratio & 0.91 & 0.91 & 0.90 & 0.90 & 0.89 & 0.94 \\
\hline Water & 165 & 156.75 & 156.75 & 140.4 & 140.4 & 143.1 \\
\hline CR2 8/20 mm & 682.6 & 694.3 & 694.3 & 713.2 & 713.2 & 710.8 \\
\hline CR1 4/10 mm & 273.6 & 278.3 & 278.3 & 285.9 & 285.9 & 284.9 \\
\hline FR2 $0 / 4 \mathrm{~mm}$ & 589.9 & 600 & 600 & 616.4 & 616.4 & 614.3 \\
\hline FR1 $0 / 2 \mathrm{~mm}$ & 188.9 & 192.1 & 192.1 & 197.4 & 197.4 & 196.7 \\
\hline $\mathrm{S} *(\%)$ & 1 & 1 & 1 & 1.2 & 1 & 1.3 \\
\hline $\mathrm{P} *(\%)$ & 1.5 & 2 & 2.5 & 2.5 & 2.7 & 3 \\
\hline \multicolumn{7}{|c|}{ WORKABILITY (slump test in $\mathrm{cm}$ ) } \\
\hline$t=0 \mathrm{~min}$ & 21.5 & 17 & 20 & 20 & 11 & 22 \\
\hline$t=30 \mathrm{~min}$ & 7 & - & 3.5 & - & 6 & 18 \\
\hline$t=60 \mathrm{~min}$ & - & - & - & - & - & 6.5 \\
\hline
\end{tabular}

* The amount of $\mathrm{S}$ and $\mathrm{P}$ used in concrete production is defined as per cent of the cement weight.

All the produced concretes' workability and slump value were determined following the UNE-EN 123350-2:2020 specifications. The slump values were determined immediately after concrete casting $(t=0 \mathrm{~min})$ and $30 \mathrm{~min}$ or $60 \mathrm{~min}$ after concrete casting $(t=30 \mathrm{~min}$ or $t=60 \mathrm{~min}$ ). Between $0 \mathrm{~min}$ (immediately after concrete casting) and $30 \mathrm{~min}$ or $60 \mathrm{~min}$, the concrete mixture was kept in the mixer, which was stopped and covered with a plastic sheet until the test time elapsed. The concrete was then mixed for one minute before the slump was again measured.

The concrete specimens were produced and cured following UNE-EN 12,390-2:2001 regulations and manually compacted using a steel rod. The concrete specimens were then covered with a plastic sheet and air-cured for the first $24 \mathrm{~h}$.

After $24 \mathrm{~h}$ of casting, the concrete specimens were demoulded and stored in the humidity room at $22{ }^{\circ} \mathrm{C}$ and $95 \%$ humidity until tested. In the concretes' hardened state, the compressive strength at 7, 28 and 56 days were determined following UNE-EN 123903:2020 specifications using cylindrical specimens of diameter $\varnothing 100 \times 200 \mathrm{~mm}$ in length. In addition, the physical properties at 28 days were determined following UNE-EN 123907:2020 specifications using cubic specimens of $100 \times 100 \times 100 \mathrm{~mm}$. Drying shrinkage was measured using concrete prismatic specimens of $70 \times 70 \times 285 \mathrm{~mm}$, exposed to $20 \pm 2{ }^{\circ} \mathrm{C}$ and relative humidity $55 \pm 5 \%$ for 56 days following UNE-EN 12390-16:2020 specifications. Each result represented the average of three measurements. 


\subsubsection{Pavement-Base Construction}

In May 2021, a $500 \mathrm{~m}$ long pavement-base layer with a 30-cm thickness (highlighted in green in Figure 4) in Passeig de Colom (PC) in Barcelona, Spain was constructed. Plain concrete with a minimum of $20 \mathrm{MPa}$ compressive strength was manufactured using FR1, FR2, CR1 and CR2 fractions. In addition, more than $815 \mathrm{~m}^{3}$ of washed recycled aggregates were employed in pavement-base layer construction.

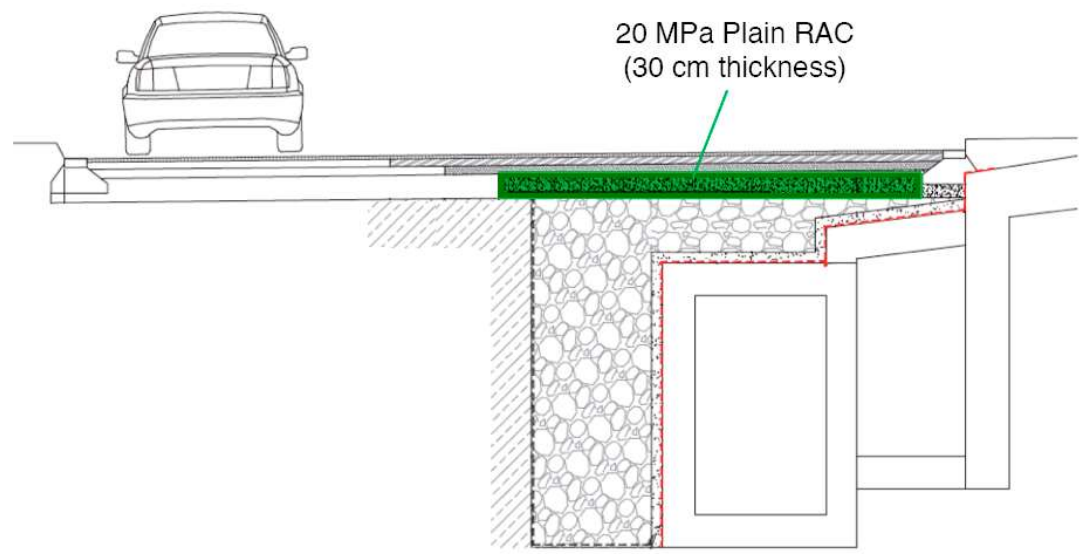

Figure 4. Section of pavement-base built using 100\% recycled aggregate.

Table 5 describes the three-mix proportions employed for pavement-base layer construction. The humidity of the aggregates was determined before producing the concretes, except for the first day RAC-300-PC1 concrete. The humidity was determined after concrete production and was higher than initially estimated. The average humidity values (and its standard deviation) of the FR1, FR2, CR1 and CR2 recycled aggregates were $21.5 \%(1.2 \%)$, $9.9 \%(0.4 \%), 6.4 \%(0.2 \%)$ and $4.9 \%(0.5 \%)$, respectively. The fine recycled aggregates (FR1 and FR2) had higher-humidity concretes produced in the laboratory. The concrete mixture used for pavement-base layer construction was designed with $300 \mathrm{~kg}$ of cement and an effective water/cement ratio of $0.52-0.53$ to assure the minimum strength of $20 \mathrm{MPa}$. However, because the humidity of the aggregates used in RCA-300-PC1 concrete production was higher than the estimated values, the RAC-300-PC1 concrete was produced with an effective water/cement ratio of 0.59 . The rest of the pavement-base layer production was constructed using the RCA-300-PC2 and RCA-300-PC3 concretes, with effective water/cement ratios of 0.52 and 0.53 , respectively.

Table 5. Mix proportions of the concrete produced. The values are given as weight (in humid conditions) over the volume of concrete production $\left(\mathrm{kg} / \mathrm{m}^{3}\right)$.

\begin{tabular}{cccc}
\hline & RAC-300-PC1 & RAC-300-PC2 & RAC-300-PC3 \\
\hline CEM II A-L 42.5 & 300 & 300 & 300 \\
\hline TOTAL water & 101.5 & 88.0 & 97.4 \\
\hline Efective w/c ratio & 0.59 & 0.52 & 0.53 \\
\hline FR1 0/2 mm & 246.4 & 253.3 & 244.8 \\
\hline FR2 0/4 mm & 688.8 & 708.1 & 702.3 \\
\hline CR1 4/10 mm & 274.1 & 281.8 & 280.5 \\
\hline CR2 8/20 mm & 665.3 & 683.9 & 691.5 \\
\hline S ** $(\%)$ & $1.05+0.2$ & $1.05+0.2$ & $1.05+0.2$ \\
\hline P $(\%)$ & 1 & 1 & 1 \\
\hline
\end{tabular}

** S and P: \% of admixture for the cement weight. The second quantity of superplasticizer (+0.2) was added directly to the truck on-site to increase the workability of the concrete for placement in suitable conditions since the concrete arrived at the site one hour after its manufacture. 
All the concretes' workability and slump values were determined on-site (see Figure 5a-c).

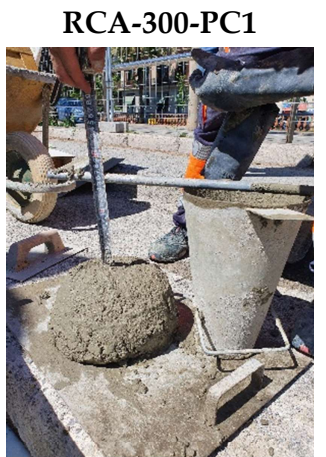

(a) Slump: $15 \mathrm{~cm}$

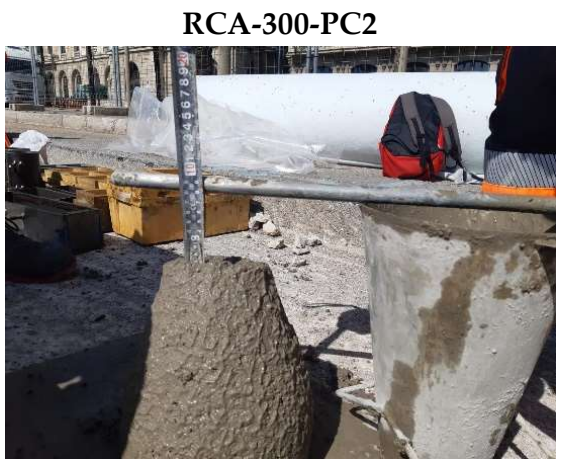

(b) Slump: $8 \mathrm{~cm}$

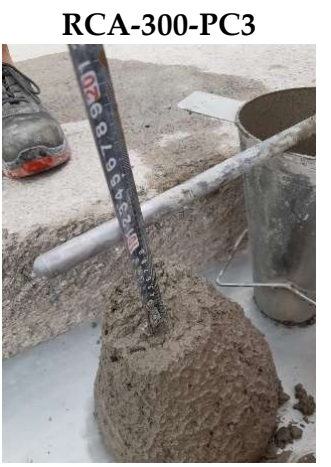

(c) Slump: $10 \mathrm{~cm}$

Figure 5. On-site slump test determination.

The concrete mixtures were placed on-site directly from the truck (see Figure 6a). After compaction using a needle vibrator (see Figure $6 b$ ), the admixture of acrylic resin-based evaporation reducer, curing improvement admixture, was added to the concrete surface (see Figure 6c) to guarantee an adequate curing process. Figure 6 summarises the concrete laying process.

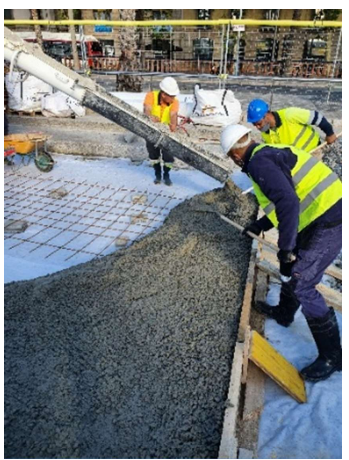

(a)

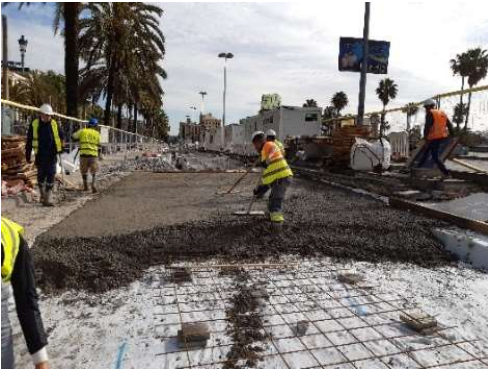

(b)

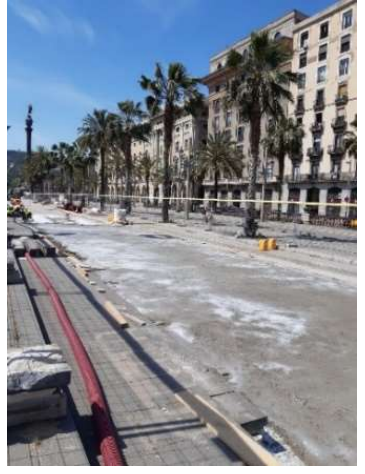

(c)

Figure 6. On-site concrete laying (a), compaction (b) and curing process (c) of the concrete.

Concrete specimens were fabricated to characterise the produced concretes. The concrete samples were manually compacted using a steel rod. The specimens were then covered with a plastic sheet and air-cured for the first $24 \mathrm{~h}$ at the worksite. After $24 \mathrm{~h}$ of casting, the concretes specimens were moved to the university laboratory, demoulded and stored in the humidity room until the required testing. The mechanical properties of compressive and flexural strength were determined. The compressive strength at 7, 14, 28 and 56 days was determined for cylindrical specimens of $\varnothing 100 \mathrm{~mm} \times 200 \mathrm{~mm}$ and cubic specimens of $150 \times 150 \times 150 \mathrm{~mm}$ for 28 days. In addition, the flexural strength was determined using prismatic samples of $100 \times 100 \times 400 \mathrm{~mm}$ at 28 days of curing. The physical properties at 28 days were determined using cubic specimens of $100 \times 100 \times 100 \mathrm{~mm}$. Finally, the durability properties of drying shrinkage and depth of penetration of water under pressure were determined. The drying shrinkage was determined using $70 \times 70 \times 285 \mathrm{~mm}$ specimens. Cylindrical specimens of $\varnothing 100 \times 200 \mathrm{~mm}$ were used to calculate the penetration depth, following UNE-EN 12,390-8:2020 specification. Each result was recorded as the average of three measurements. 


\section{Results}

\subsection{Laboratory Work: Phase 1}

\subsubsection{Workability of Produced Concrete}

Table 4 shows the workability achieved of all the concretes produced. The RCA-300 concrete achieved an initial slump value of $21.5 \mathrm{~cm}$ and adequate laying properties with $7 \mathrm{~cm}$ of slump value after $30 \mathrm{~min}$ of production. It was produced with an effective and total water/cement ratios of 0.55 and 0.91 , respectively. In addition, $1 \%$ and $1.5 \%$ of admixtures $\mathrm{S}$ and $\mathrm{P}$, respectively, were used for concrete production.

The concrete produced with $285 \mathrm{~kg}$ of cement (RCA-285) with S 1\% and P 2.5\% achieved an initial slump value of $20 \mathrm{~cm}$. However, after $30 \mathrm{~min}$ of casting, the slump value dropped to $3.5 \mathrm{~cm}$, too dry to lay it on-site under normal conditions. The RCA-285 concrete was also produced with an effective water/cement ratio of 0.55 , but with a little less cement. Consequently, the water amount employed was also lower than that used for RCA-300 production. Thus, the RCA-285 concrete would initially require a slightly higher $S$ admixture and a somewhat higher slump value.

The concretes produced with a lower cement amount (RAC-270) were produced with a lower effective $\mathrm{w} / \mathrm{c}$ ratio (0.52-0.53). Consequently, they needed more admixtures to achieve a good slump value. The RCA-270-1 concrete using S 1\% and P $2.7 \%$ achieved a slump value of $6 \mathrm{~cm}$ at $30 \mathrm{~min}$. The RCA-270-3 concrete with S 1.3\% and P 3\% achieved a slump test of $6.5 \mathrm{~cm}$ at $60 \mathrm{~min}$. Therefore, an amount slightly higher than $1 \% \mathrm{~S}$ admixture (reached $1.3 \%$ ) together with up to $3 \% \mathrm{P}$ was necessary for an adequate slump value at 30 or 60 min after casting.

\subsubsection{Hardened Properties of Concrete}

The hardened properties were determined only in concretes with an initial slump value $\geq 20 \mathrm{~cm}$. Table 6 shows the mechanical and physical properties obtained by the produced concretes. All the produced concretes achieved the required compressive strength of $20 \mathrm{MPa}$ at 28 days, reaching similar values to those obtained by other researchers [41]. While the RCA-300 concrete achieved a strength of $29.7 \mathrm{MPa}$ at 28 days, the RCA-2852 concrete achieved a strength value of $30.4 \mathrm{MPa}$. However, as shown in Table 4, the RCA-285-2 concrete failed to reach an adequate slump value.

Table 6. The mechanical and physical properties of concretes produced in the laboratory.

\begin{tabular}{cccccccc}
\hline & \multicolumn{2}{c}{ Compressive Strength (MPa) } & $\begin{array}{c}\text { Flexural Strength } \\
(\mathbf{M P a})\end{array}$ & $\begin{array}{c}\text { Dry Density } \\
\left(\mathbf{k g} / \mathbf{d m}^{\mathbf{3}}\right)\end{array}$ & $\begin{array}{c}\text { Absorption } \\
\mathbf{( \% )}\end{array}$ & $\begin{array}{c}\text { Accesible } \\
\text { Porosity (\%) }\end{array}$ \\
\hline Concrete Type & 7 Days & 28 Days & 56 Days & 28 Days & 28 Days & 28 Days & 28 Days \\
\hline RCA-300 & $25.5(0.8)$ & $29.7(0.6)$ & $30.7(0.5)$ & $3.86(0.02)$ & 2.10 & 6.06 & 12.74 \\
\hline RCA-285-2 & $25.9(0.2)$ & $30.4(1.0)$ & $32.3(1.0)$ & - & 2.11 & 5.65 & 11.90 \\
\hline RCA-270-1 & $22.4(0.4)$ & $26.0(0.8)$ & $26.9(0.9)$ & - & 2.06 & 5.97 \\
\hline RCA-270-3 & $19.9(1.8)$ & $26.4(0.6)$ & $27.2(0.6)$ & - & 2.09 & 6.83 & 12.30 \\
\hline
\end{tabular}

In addition, the RAC-270 concrete, produced with $270 \mathrm{~kg}$ of cement, achieved a compressive strength of $26 \mathrm{MPa}$ at 28 days, with an acceptable slump value (see Table 4), thus being adequate for the defined application. However, it should be noted that the RCA270-3 concrete achieved the lowest strength value at seven days and the highest standard deviation, probably due to the use of P 3\% admixture. Nevertheless, the compressive strength increase from 7 days to 28 days was $34 \%$ (due to effective of $3 \%$ P [5]) compared to the other concrete, which rose to $16.5 \%$ during the same period. All the produced concretes achieved a similar compressive strength increase of 3-6\% from 28 to 56 days of curing. In addition, the standard deviation of compressive strength values was low in all the concretes. The flexural strength was only determined in RCA-300, guaranteeing that this concrete would be adequate for a pavement-base application [42]. 
A study of the physical properties achieved, showed that all the produced concretes had a lower dry density and higher absorption capacity than conventional concrete and concrete using only coarse RCA [43,44]. It was also determined that they achieved similar densities to those concretes produced with 100\% coarse recycled mixed aggregates [45]. In addition, the RCA-270-3 achieved the highest porosity, as it combined the lowest cement amount of $270 \mathrm{~kg}$, a higher water/cement ratio than RCA-270-1 and the highest $\mathrm{P}$ admixture. However, the obtained values were shown to be similar to values achieved by various researchers' concretes, which were produced with $100 \%$ coarse and fine aggregates [41]. Consequently, they are acceptable for non-structural plain concrete pavementbase applications [42].

Figure 7 shows the obtained drying shrinkage values (Figure 7a) and the mass loss (Figure 7b) of the produced four concretes. The obtained values in the four concretes were alike as they employed similar amounts of recycled aggregates and total water in all the produced concretes. The value of all the concretes reached $-1000 \mu \epsilon$ in 56 days. In addition, according to ACI [46], the typical drying shrinkage values were -200 to -800 in conventional concrete when a high water/cement ratio was used. The drying shrinkage of concrete with recycled aggregates is always higher than that produced with natural aggregates due to the reduced restraint of recycled aggregate and the high water content [33], reaching to high shrinkage values when $100 \%$ of fine and coarse aggregates are employed [47]. However, most of the research works carried out up to date have only analysed concretes using recycled coarse aggregates [48]. In addition, Figure $7 \mathrm{~b}$ shows that all the concrete mixtures achieved a mass loss \% of $4.25 \%$ after 56 days of drying test exposure.

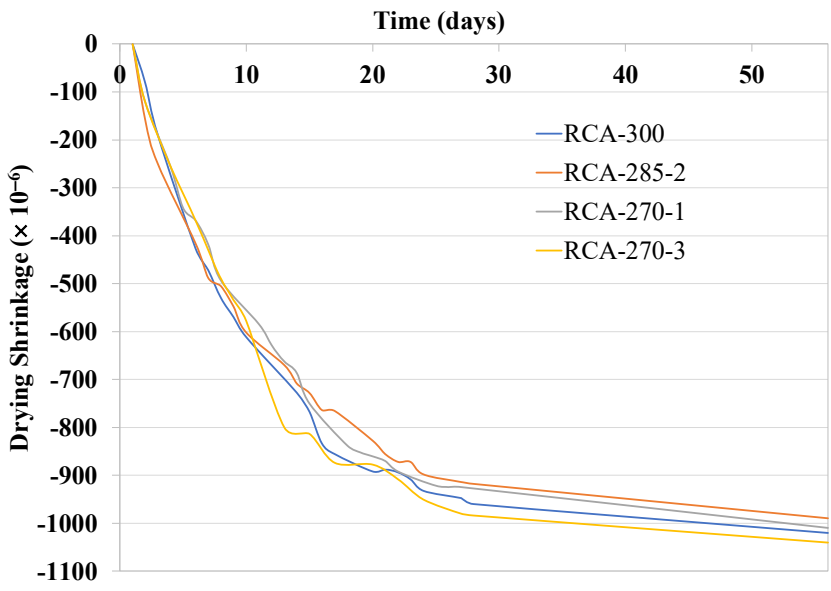

(a)

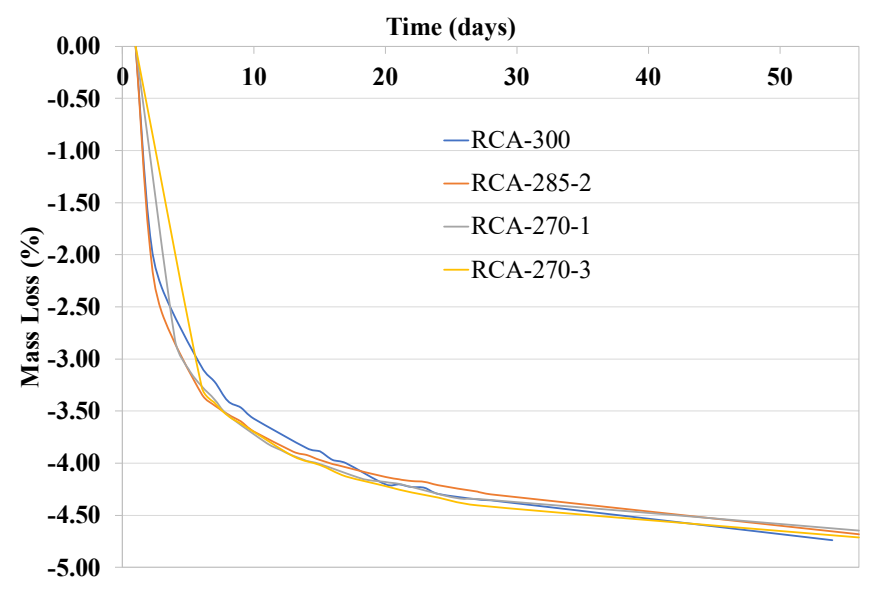

(b)

Figure 7. (a) drying shrinkage $\left(\times 10^{-6}\right)$ and $(\mathbf{b})$ mass loss $(\%)$ of the concrete samples.

Figure 8 shows the relationship between weight loss \% and shrinkage value of the four concretes. The concrete RCA-270-1 and RCA-270-3 produced with the highest volume of recycled aggregates suffered a higher mass loss with very low shrinkage value. In addition the RCA-270-3, produced with the highest total w/c ratio, suffered more than $3 \%$ mass loss with a shrinkage value of $-120 \mu \epsilon$. However, all the concretes achieved similar last shrinkage and total mass loss (\%) values. 


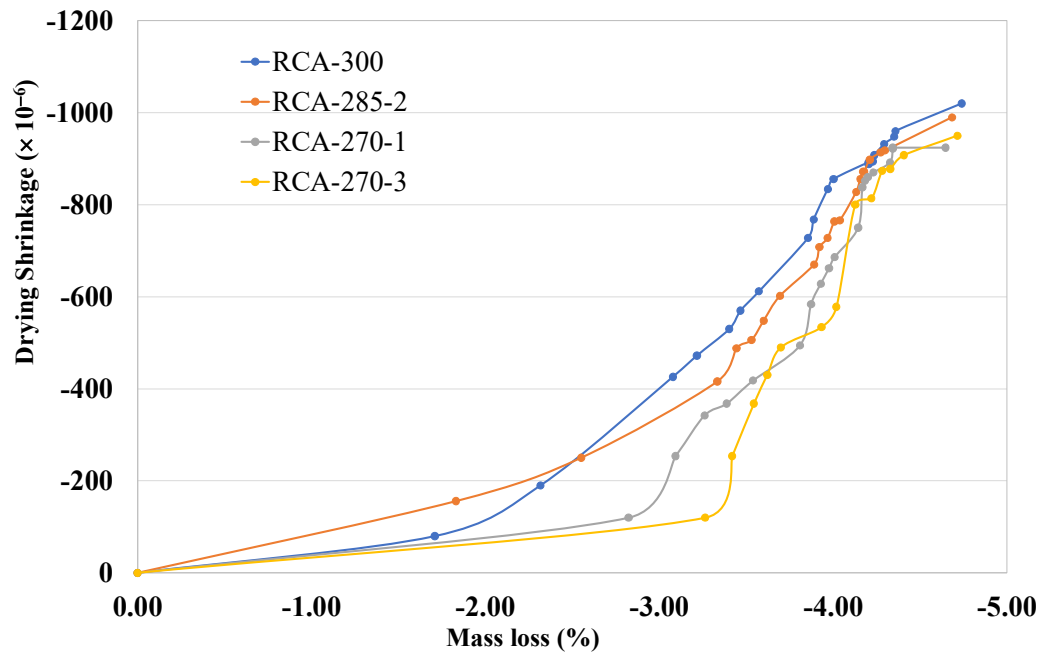

Figure 8. Relationship between mass loss (\%) and drying shrinkage value.

\subsection{Pavement-Base Construction}

\subsubsection{Workability of Concrete Produced}

Figure 5 shows the slump values for the three concrete mixtures produced. All concrete included 1\% S and 1\% P in the production process. The recycling plant and concrete producer were located $25 \mathrm{~km}$ from Barcelona. However, heavy morning traffic at the entrance to Barcelona caused huge delays. Under those conditions, the trip could take up to $50 \mathrm{~min}$. When the truck arrived, all the concrete mixtures had a slump lower than $5 \mathrm{~cm}$. Consequently, to increase the concrete workability, it was necessary to add $0.20 \% \mathrm{~S}$ to the concrete mixture. After mixing the concrete for $10 \mathrm{~min}$, slump values of $15 \mathrm{~cm}, 8 \mathrm{~cm}$ and $10 \mathrm{~cm}$ were determined for the RCA-300-PC1, PCA-300-PC2, and RCA-300-PC3 concretes, respectively (Figure 5). The RCA-300-PC1 was produced with the highest water/cement ratio, achieving the highest slump. The PCA-300-PC2 and RCA-300-PC3 concretes were made with a similar effective $\mathrm{w} / \mathrm{c}$ ratio and reached a similar adequate slump value.

\subsubsection{Hardened Properties of Concrete}

Table 7 shows the results obtained for the pavement concrete. The RCA-300-PC1 concrete achieved a lower strength due to a higher effective water/cement ratio (see Table 5) in its production than the RCA-300-PC2 and RCA-300-PC3 concrete. However, all concretes achieved the minimum required $20 \mathrm{MPa}$ and a low standard deviation value. The water-washed recycled aggregates had a positive effect, reaching a low standard deviation for the mechanical results.

Table 7. The mechanical properties of produced pavement-base concrete. The standard deviation of the obtained results is described between the brackets.

\begin{tabular}{ccccc}
\hline & \multicolumn{3}{c}{ Compressive Strength (MPa) } & Flexural \\
& 7 Days & 28 Days * & 56 Days & 28 Days \\
\cline { 2 - 5 } & $19.0(0.2)$ & $21.8(0.2)$ & $23.9(0.6)$ & $3.6(0.3)$ \\
\hline RCA-300-PC1 & $21.2(0.1)$ & $25.7(0.7)$ & $27.9(0.7)$ & $3.6(0.5)$ \\
\hline RCA-300-PC2 & $23.6(0.4)$ & $30.1(0.6)$ & $31.5(1.4)$ & $3.5(0.2)$ \\
\hline RCA-300-PC3 &
\end{tabular}

* Specimens of different shapes were tested. However, all the results were evaluated as cylindrical specimens.

The flexural strength of the concretes was similar in all concretes produced, with a value of 3.6 MPa. Other researchers [41] obtained a similar value, which could also be valid for higher pavement requirements limited to 3.5 $\mathrm{MPa}$ [42]. The flexural strength not only depends on the effective $\mathrm{w} / \mathrm{c}$ ratio used but also on the effectiveness of the bonding zone 
between the cement paste and the aggregate, on the quality of the aggregate to adhere to the cement paste $[31,32]$. In this case, all the concretes were manufactured with the same quantity and quality of aggregates.

Table 8 describes the physical properties of concrete and the depth of water penetration under the pressure of the produced concretes. The concretes reached low densities, caused by the density of the recycled aggregates used in $100 \%$ of the aggregate volume in the mixture [27]. In addition, the water absorption capacity was also high and higher in concrete produced with a higher water/cement ratio (RCA-300-PC1) [27,41]. It must be noted that since there was no presence of contaminants in the aggregates, and the aggregates and the cement used had good compatibility, these properties did not present any disadvantage for the durability of this plain concrete.

Table 8. The physical properties and depth of water penetration under pressure in produced concrete.

\begin{tabular}{|c|c|c|c|c|}
\hline & \multirow{2}{*}{ Dry Desity $\left(\mathrm{kg} / \mathrm{dm}^{3}\right)$} & \multirow{2}{*}{ Absorption (\%) } & \multicolumn{2}{|c|}{ Depth of Penertation (cm) } \\
\hline & & & Average & Max \\
\hline RCA-300-PC1 & 2.02 & 8.37 & 5.9 & 6.3 \\
\hline RCA-300-PC2 & 2.04 & 7.72 & 1.6 & 2.1 \\
\hline RCA-300-PC3 & 2.07 & 7.15 & 1.6 & 2.1 \\
\hline Structural Code requirement & - & - & 3 & 5 \\
\hline
\end{tabular}

According to the Structural Code, the maximum and average water penetration depth under pressure should be $5 \mathrm{~cm}$ and $3 \mathrm{~cm}$, respectively. However, the RCA-300-PC1 reached a higher penetration depth than the code required (see Table 8 and Figure $9 a-c$ ) caused by a concrete mixture with a water/cement ratio that was too high. The other two concretes, RCA-300-PC2 and RCA-300-PC3, employed in all the pavements volume except the first casting, achieved adequate properties in concretes for structural code requirements. However, this concrete was designed as a pavement-base layer (non-structural element). Consequently, it did not need to achieve the requirements of structural concrete.

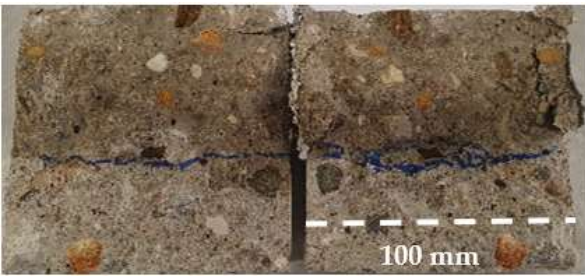

(a) RCA-300-PC1

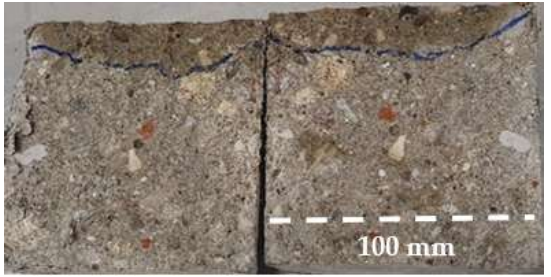

(b) RCA-300-PC2

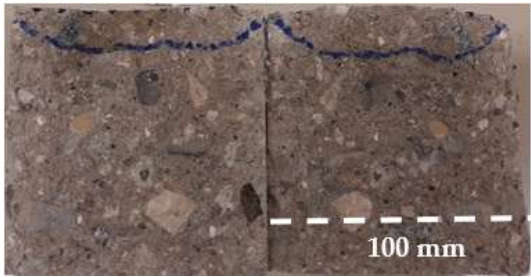

(c) RCA-300-PC3

Figure 9. Depth of penetration of water under pressure of three mixtures $(\mathbf{a}-\mathbf{c})$.

Figure 10 shows the obtained drying shrinkage values (Figure 10a) and the mass loss (Figure 10b) of the specimens produced in three different mixtures. As described above, the drying shrinkage was high due to the high water content in the $100 \%$ of coarse and fine recycled aggregate employed, concrete production [33]. In addition, the mass loss was 4\% in concretes. The obtained values were very similar to those of the laboratory. 


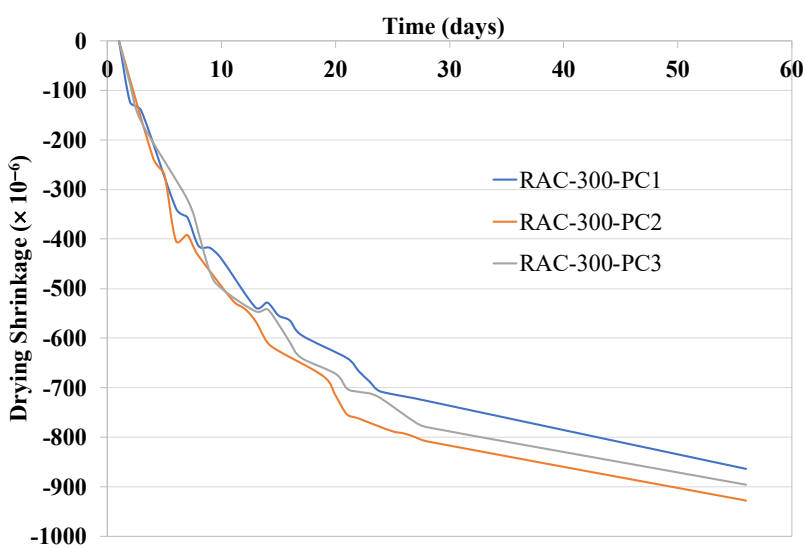

(a)

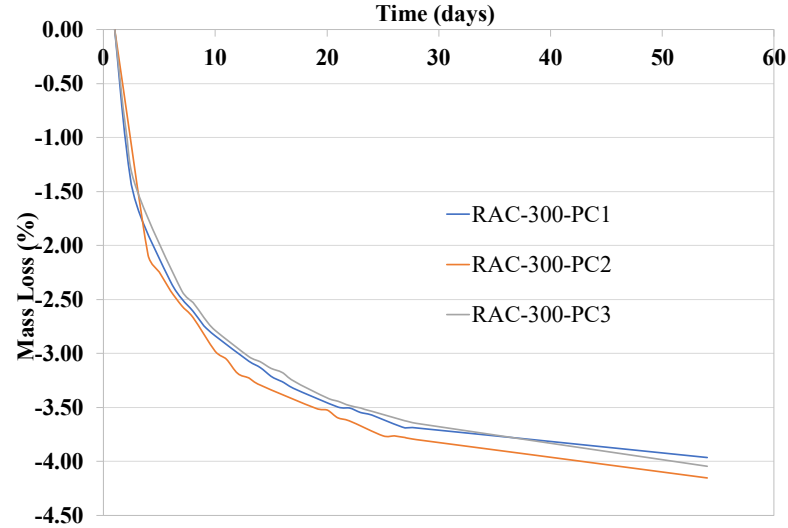

(b)

Figure 10. (a) drying shrinkage $\left(\times 10^{-6}\right)$ and (b) mass loss $(\%)$ of the concrete samples.

The relationship between the mass loss \% and shrinkage value of concrete mixtures of the three concrete mixtures was similar. The three concretes achieved similar total shrinkage and total mass loss (\%) values (see Figure 11).

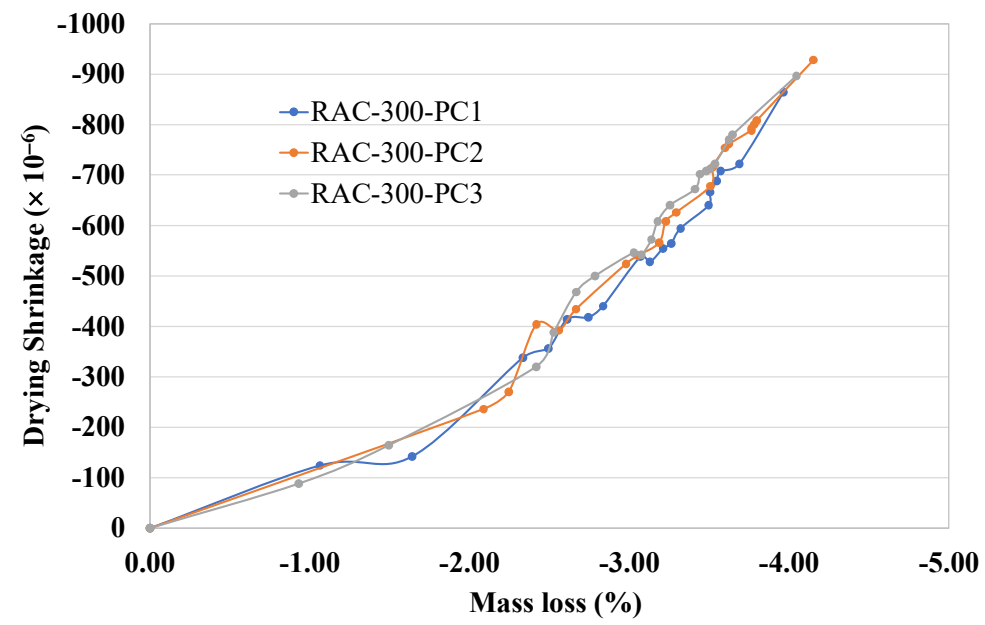

Figure 11. Relationship between mass loss (\%) and drying shrinkage value of concrete mixtures of pavement.

\section{Discussion}

\subsection{Workability}

The obtained results determined that the workability was difficult to maintain over a sustained period of time when the concrete was produced using C-RCA and F-RCA aggregates. Several researchers [49] reached a similar conclusion regarding the packing effect of recycled sand, surface roughness of the particles and loss of chemical admixtures efficiency due to mortar adherence.

Laboratory analysis determined that an initial slump $>20 \mathrm{~cm}$ was needed to achieve a good $(6-8 \mathrm{~cm})$ slump value of 30 or more minutes after concrete production. In addition, the combination of both admixtures, the high water-reducing superplasticiser (S) and multifunctional admixture $(\mathrm{P})$, were necessary to achieve adequate workability. The RCA300 concrete achieved sufficient but limited workability using $1 \% \mathrm{~S}$ and $1.5 \% \mathrm{P}$ within the admixtures producer's recommendations. However, reducing the amount of cement and the effective water/cement ratio employed in RCA-285 and RCA270 concretes resulted in the need for a higher admixture to achieve adequate workability. RCA-270-3 concrete with S 1.3\% and P 3\% achieved acceptable slump values of $6.5 \mathrm{~cm}$ at 60 min after casting. 
The multifunctional admixture $(\mathrm{P})$ was required for use in a higher volume than that defined by its manufacturers to achieve adequate workability after $30 \mathrm{~min}$ of production. Tahar et al. [49] found that bad retention rheology was observed when the concrete was made with $100 \%$ F-RCA. In addition, they also used double the volume of admixtures in recycled concrete than conventional concrete to achieve workability similar to conventional concrete. However, a high amount of $\mathrm{P}$ admixture could retard the setting time in the winter season and should be validated.

In the pavement-based layer construction (industrial-scale), the concrete producers used a limited $1 \% \mathrm{~S}$ and $1 \% \mathrm{P}$ for concrete production. The concrete mixtures had a dry consistency when the trucks arrived at the worksite. Consequently, a $0.2 \% \mathrm{~S}$ admixture was added into the ready-mix truck before concrete laying, achieving adequate workability in all the concretes. However, a higher S plus $\mathrm{P}$ was required to offset the concrete mixer driver's likelihood of adding water to the concrete to achieve a workable mixture. Gress et al. [12] also described that the recycled pavement concrete mixtures (using 100\% C-RCA and up to $25 \%$ F-RCA) generally exhibited reduced workability due to the inherent angularity, rough surface texture, and high absorption characteristics of the RCA, being necessary to use water reducers, or fly ash to improve workability. Sadati and Khayat [9] described that did not have problem with placement, finishing and tinning at the job site, which included casting $450 \mathrm{~m}^{3}$ of concrete in a length of $300 \mathrm{~mm}$ when the concrete produced with $40 \%$ of C-RCA had a slump value of $35 \mathrm{~mm}$.

\subsection{Hardened State Properties}

All the concretes produced in the laboratory achieved the required $20 \mathrm{MPa}$ for the application. Initially, $300 \mathrm{~kg}$ of cement $/ \mathrm{m}^{3}$ of concrete was used, which reached adequate compressive and flexural strength with a low standard deviation. Moreover, the concrete produced with $270 \mathrm{~kg}$ of cement per $\mathrm{m}^{3}$ also achieved a higher compressive strength than the minimum required for the application $(20 \mathrm{MP})$. This concrete is the most acceptable from an environmental point of view. RCA-270 concrete employed $100 \%$ of recycled aggregates (fine and coarse), achieving circularity by re-introducing the construction and demolition waste as recycled aggregates into the production process. In addition, the over-exploitation of raw materials is reduced, maximising material life cycles [3]. Moreover, the RCA-270 concrete used the lowest amount of cement. Consequently, it also has the lowest contribution to global warming potential (GWP) by employing a lower amount of cement than any other concrete [50].

For industrial use, the pavement-base layer was produced using $300 \mathrm{~kg}$ of cement per $\mathrm{m}^{3}$ of concrete. Although the concrete mix proportion was validated in the laboratory before being used in pavement construction, the first mixture (RCA-300-PC1) was produced using an effective water/cement ratio of 0.59 , which proved to be too high in order to achieve the minimum strength required. When the recycled aggregates were used under high humidity, an effective water/cement ratio of $0.53-0.52$ was required.

The density and absorption values obtained in laboratory and pavement construction concretes were comparable. They achieved lower and higher values, respectively, than those usually achieved by conventional concrete [27] and concrete produced using only C-RCA or F-RCA $[27,33]$. However, the depth of water penetration under pressure was below the maximum limit (except RCA-300-PC1 concrete made with a water/cement ratio of 0.59 ). Thomas et al. [51] concluded that permeability depended on the effective water/cement ratio.

In addition, the drying shrinkage values were high due to the low stiffness of RCA and high water accumulation by the RCA aggregates due to their high water absorption capacity $[5,33]$. The concretes produced in the laboratory and pavement construction achieved values similar to 950 microstrains drying shrinkage and $4.25 \%$ mass loss. As a consequence of the high strain value obtained, an admixture of acrylic resin-based evaporation reducer for concrete surfaces was applied (see Figure 6c) to reduce cracking risk. Sadati and Khayat [9] also described that increasing the w/c ratio increased the 
shrinkage value of pavement concretes. They too sprayed a liquid curing compound on the finished surfaces after finishing.

The high drying shrinkage limited the use of RAC in structural applications due to two effects: (1) excessive shrinkage deformation could endanger the safety of the structure because shrinkage of concrete plays a significant role in the design of the service limit state of structural members [33,48,52]; and (2) higher shrinkage may cause cracks. This could affect the overall performance of concrete and enable the ingress of harmful substances, resulting in the corrosion of structural concrete reinforcement [5]. However, the plain concrete pavement-base this risk does not occur as it is not reinforced.

\section{Conclusions}

The following conclusions are based on the results of our study of concrete made with 100\% coarse and fine RCA for a pavement-base layer:

- The water-washed RCA achieved type A category, aggregates for concrete, adequate for pavement-base layer construction. In addition, the coarse and fine RCA fractions achieved an absorption capacity lower than $7 \%$, and their physical and mechanical properties and chemical components fulfilled the requirements for use in structural concrete.

- The properties of the pavement-base layer concrete produced on the worksite were similar to those obtained in the laboratory. Consequently, the laboratory results were validated for high-scale production.

- All recycled concrete achieved adequate initial workability. However, to achieve an extended slump value (minimum for $30 \mathrm{~min}$ ), a value of $3 \%$ multifunctional admixture plus $1-1.2 \%$ superplasticiser must be used in concrete production.

- On the worksite, a lower chemical admixture was employed, causing a dry consistency, and requiring $0.20 \%$ superplasticiser.

- All concretes achieved the required strength of $20 \mathrm{MPa}$. The concrete produced with $270 \mathrm{~kg}$ of cement per $\mathrm{m}^{3}$ and a water/cement ratio of 0.53 resulted in the best properties with the lowest environmental impact.

- The concretes presented a high absorption capacity. However, the water penetration depth under pressure value was below the maximum limit established by the structural code when the recycled concretes were produced with a water/cement ratio of 0.53 independent of the amount of cement used.

- The drying shrinkage was high due to the employment of $100 \%$ of recycled aggregate concrete. Although there was no cracking in the concrete measured in the laboratory specimens, it is possible that the concrete could suffer high strain in low humidity days. However, pavement-base case is a non-structural plain concrete and consequently, problems with deformation and cracking to ingress harmful substances, resulting in corrosion cannot happen.

The water-washed recycled aggregates do not include filler or any chemical components. In addition, they have good physical and mechanical properties for use in structural concrete production. The employment of $100 \%$ coarse and fine RCA in concrete production causes a considerable increase in drying shrinkage. This could increase deformation, significantly reducing the service life of structural members and the risk of cracking, enabling the ingress of harmful substances. However, non-structural elements do not have those limitations, and they allow the massive volume of recycled aggregates validated in this case study to be employed. The authors believe it is a straightforward, simple way to re-circulate construction and demolition waste.

Author Contributions: Conceptualization, M.E. and M.Á.P.; methodology, M.E., M.K. and C.G.; validation, M.E., M.K., C.G. and M.Á.P.; investigation, M.E., M.K. and C.G.; resources, M.E. and M.Á.P.; writing — original draft preparation, M.E.; writing-review and editing, M.E.; project administration, M.E.; funding acquisition, M.E. and M.Á.P. All authors have read and agreed to the published version of the manuscript. 
Funding: This research received no external funding.

Institutional Review Board Statement: Not applicable.

Informed Consent Statement: Not applicable.

Data Availability Statement: Not applicable.

Acknowledgments: The authors thank Ajuntament de Barcelona (Barcelona city council), Bimsa and SBS Simón i Blanco for their courage and support in working with recycled aggregate concrete. The first author also wants the staff of the Laboratory of Technology of Structures and Materials "Lluis Agulló" of the UPC for their support.

Conflicts of Interest: The authors declare no conflict of interest.

\section{References}

1. Tam, V.W.Y.; Soomro, M.; Evangelista, A.C.J. A review of recycled aggregate in concrete applications (2000-2017). Constr. Build. Mater. 2018, 172, 272-292. [CrossRef]

2. European Statistics-Eurostat. Energy, Transport and Environment Statistics 2020 Edition; Publications Office of the European Union: Luxembourg, 2020; ISBN 9789276207375.

3. European Commission. Communication from the Commission to the European parliament, the council, the European Economic and Social Committee and the Committee of the regions. Next steps for a sustainable European future European action for sustainability, Strasbourg, France, 2016. Available online: https://eur-lex.europa.eu/legal-content/EN/TXT/?uri=COM\%3A201 6\%3A739\%3AFIN (accessed on 6 January 2022).

4. Plaza, P.; del Bosque, I.S.; Frías, M.; de Rojas, M.S.; Medina, C. Use of recycled coarse and fine aggregates in structural eco-concretes. Physical and mechanical properties and CO2 emissions. Constr. Build. Mater. 2021, 285, 122926. [CrossRef]

5. Neville, A.M.; Neville, A.M. Properties of Concrete; Pearson Education Limited: London, UK, 2011; ISBN 9780273755807.

6. Renan Sorato, S.P.; Venkateswarlu, B. Recycled aggregate concrete; an overview. J. Struct. Eng. 2016, 18, 67-75.

7. Nwakaire, C.M.; Yap, S.P.; Onn, C.C.; Yuen, C.W.; Ibrahim, H.A. Utilisation of recycled concrete aggregates for sustainable highway pavement applications; a review. Constr. Build. Mater. 2019, 235, 117444. [CrossRef]

8. Selvam, M.; Debbarma, S.; Singh, S.; Shi, X. Utilization of alternative aggregates for roller compacted concrete pavements-A stateof-the-art review. Constr. Build. Mater. 2021, 317, 125838. [CrossRef]

9. Sadati, S.; Khayat, K. Field performance of concrete pavement incorporating recycled concrete aggregate. Constr. Build. Mater. 2016, 126, 691-700. [CrossRef]

10. Cuttell, G.D.; Snyder, M.B.; Vandenbossche, J.M.; Wade, M.J. Performance of Rigid Pavements Containing Recycled Concrete Aggregates. Transp. Res. Rec. J. Transp. Res. Board 1997, 1574, 89-98. [CrossRef]

11. Nassar, R.; Soroushian, P. Use of recycled aggregate concrete in pavement construction. J. Solid Waste Technol. Manag. 2016, 42, 137-144. [CrossRef]

12. Gress, D.L.; Snyder, M.B.; Sturtevant, J.R. Performance of Rigid Pavements Containing Recycled Concrete Aggregate. Transp. Res. Rec. J. Transp. Res. Board 2009, 2113, 99-107. [CrossRef]

13. Silva, R.V.; de Brito, J.; Dhir, R.K. Use of recycled aggregates arising from construction and demolition waste in new construction applications. J. Clean. Prod. 2019, 236, 117629. [CrossRef]

14. Poon, C.S.; Chan, D. The use of recycled aggregate in concrete in Hong Kong. Resour. Conserv. Recycl. 2007, 50, 293-305. [CrossRef]

15. Zhang, H.; Zhao, Y. Performance of Recycled Aggregate Concrete in a Real Project. Adv. Struct. Eng. 2014, 17, 895-906. [CrossRef]

16. Xiao, J.; Wang, C.; Ding, T.; Nezhad, A.A. A recycled aggregate concrete high-rise building: Structural performance and embodied carbon footprint. J. Clean. Prod. 2018, 199, 868-881. [CrossRef]

17. Chen, W.; Jin, R.; Xu, Y.; Wanatowski, D.; Li, B.; Yan, L.; Pan, Z.; Yang, Y. Adopting recycled aggregates as sustainable construction materials: A review of the scientific literature. Constr. Build. Mater. 2019, 218, 483-496. [CrossRef]

18. Pedro, D.; de Brito, J.; Evangelista, L. Influence of the use of recycled concrete aggregates from different sources on structural concrete. Constr. Build. Mater. 2014, 71, 141-151. [CrossRef]

19. Etxeberria, M.; Mari, A.; Vázquez, E. Recycled aggregate concrete as structural material. Mater. Struct. 2006, 40, 529-541. [CrossRef]

20. Kirthika, S.K.; Singh, S.; Chourasia, A. Alternative fine aggregates in production of sustainable concrete-A review. J. Clean. Prod. 2020, 268, 122089. [CrossRef]

21. López-Gayarre, F.; Serna, P.; Domingo-Cabo, A.; Serrano-López, M.; López-Colina, C. Influence of recycled aggregate quality and proportioning criteria on recycled concrete properties. Waste Manag. 2009, 29, 3022-3028. [CrossRef]

22. Miren, E.; Enric, V.; Marí, A.R. Microstructure analysis of hardened recycled aggregate concrete. Mag. Concr. Res. 2006, 58, 683-690.

23. Hansen, T.C. Recycling of Demolished Concrete and Masonry; E\&FN Spon: London, UK, 1992.

24. Khatib, J.M. Properties of concrete incorporating fine recycled aggregate. Cem. Concr. Res. 2005, 35, 763-769. [CrossRef] 
25. Bogas, J.A.; de Brito, J.; Ramos, D. Freeze-thaw resistance of concrete produced with fine recycled concrete aggregates. J. Clean. Prod. 2016, 115, 294-306. [CrossRef]

26. Lavado, J.; Bogas, J.; de Brito, J.; Hawreen, A. Fresh properties of recycled aggregate concrete. Constr. Build. Mater. 2020, 233, 117322. [CrossRef]

27. Nedeljković, M.; Visser, J.; Šavija, B.; Valcke, S.; Schlangen, E. Use of fine recycled concrete aggregates in concrete: A critical review. J. Build. Eng. 2021, 38, 102196. [CrossRef]

28. Sasanipour, H.; Aslani, F. Durability properties evaluation of self-compacting concrete prepared with waste fine and coarse recycled concrete aggregates. Constr. Build. Mater. 2019, 236, 117540. [CrossRef]

29. Tobori, N.; Hosoda, T.; Kasami, H. Properties of Superplasticized Concrete Containing Recycled Fine Aggregate. In International Conference on High performance Concrete, and Performance and Quality of Concrete Structures; Farmington Hills: Gramado, RS, Brazil, 1999.

30. Pereira, P.; Evangelista, L.; de Brito, J. The effect of superplasticizers on the mechanical performance of concrete made with fine recycled concrete aggregates. Cem. Concr. Compos. 2012, 34, 1044-1052. [CrossRef]

31. Evangelista, L.; de Brito, J. Durability performance of concrete made with fine recycled concrete aggregates. Cem. Concr. Compos. 2010, 32, 9-14. [CrossRef]

32. Wang, Y.; Liu, F.; Xu, L.; Zhao, H. Effect of elevated temperatures and cooling methods on strength of concrete made with coarse and fine recycled concrete aggregates. Constr. Build. Mater. 2019, 210, 540-547. [CrossRef]

33. Zhang, H.; Wang, Y.; Lehman, D.E.; Geng, Y.; Kuder, K. Time-dependent drying shrinkage model for concrete with coarse and fine recycled aggregate. Cem. Concr. Compos. 2019, 105, 103426. [CrossRef]

34. Pacheco-Torgal, F.; Ding, Y.; Colangelo, F.; Tuladhar, R.; Koutamanis, A. Advances in Construction and Demolition Waste Recycling. Management, Processing and Enviromental Assessment, 1st ed.; Elsevier: Amsterdam, The Netherlands, 2020.

35. H-ZERO. 2021. Available online: https:// www.hercalzero.es/h-zero-planta-rcd/ (accessed on 6 January 2022).

36. Relaciones con las Cortes y Memoria Democrática; Ministry of Presidential. Codigo Estructural, España (Structural CodeConcrete). 2021. Available online: https:/ / www.boe.es/eli/es/rd/2021/06/29/470 (accessed on 6 January 2022).

37. de Brito, J.; Agrela, F.; Silva, R.V. Legal Regulations of Recycled Aggregate Concrete in Buildings and Roads. In New Trends in Eco-efficient and Recycled Concrete; Elsevier: Amsterdam, The Netherlands, 2019; pp. 509-526. [CrossRef]

38. Poon, C.; Shui, Z.; Lam, L. Effect of microstructure of ITZ on compressive strength of concrete prepared with recycled aggregates. Constr. Build. Mater. 2004, 18, 461-468. [CrossRef]

39. Evangelista, L.; Gueded, M. Microstructural Studies on Recycled Aggregate Concrete. In New Trends in Eco-Efficient and Recycled Concrete; Elsevier: Amsterdam, The Netherlands, 2019; pp. 425-451.

40. Kazmi, S.M.S.; Munir, M.J.; Wu, Y.-F.; Patnaikuni, I.; Zhou, Y.; Xing, F. Effect of recycled aggregate treatment techniques on the durability of concrete: A comparative evaluation. Constr. Build. Mater. 2020, 264, 120284. [CrossRef]

41. Revilla-Cuesta, V.; Faleschini, F.; Zanini, M.A.; Skaf, M.; Ortega-López, V. Porosity-based models for estimating the mechanical properties of self-compacting concrete with coarse and fine recycled concrete aggregate. J. Build. Eng. 2021, 44, 103425. [CrossRef]

42. Ministerio de Fomento, E. PG-3 Pliego de Prescripciones Técnicas Generales Para Obras de Carreteras y Puentes; Ministry of Public Works: Madrid, Spain, 2015. Available online: https://apps.fomento.gob.es/CVP/handlers/pdfhandler.ashx?idpub=ICW020 (accessed on 6 January 2022).

43. Etxeberria, M.; Vázquez, E.; Mari, A.; Barra, M. Influence of amount of recycled coarse aggregates and production process on properties of recycled aggregate concrete. Cem. Concr. Res. 2007, 37, 735-742. [CrossRef]

44. Thomas, J.; Thaickavil, N.N.; Wilson, P. Strength and durability of concrete containing recycled concrete aggregates. J. Build. Eng. 2018, 19, 349-365. [CrossRef]

45. Etxeberria, M.; Fernandez, J.M.; Limeira, J. Secondary aggregates and seawater employment for sustainable concrete dyke blocks production: Case study. Constr. Build. Mater. 2016, 113, 586-595. [CrossRef]

46. Mcdonald, D.B.; Brooks, J.J.; Burg, R.G.; Daye, M.A.; Gardner, N.J.; Novak, L.C. Report on Factors Affecting Shrinkage and Creep of Hardened Concrete Reported by ACI Committee 209; American Concrete Institute (ACI): Farmington Hills, MI, USA, $2014 ;$ pp. 1-12.

47. Pedro, D.; de Brito, J.; Evangelista, L. Structural concrete with simultaneous incorporation of fine and coarse recycled concrete aggregates: Mechanical, durability and long-term properties. Constr. Build. Mater. 2017, 154, 294-309. [CrossRef]

48. Mao, Y.; Liu, J.; Shi, C. Autogenous shrinkage and drying shrinkage of recycled aggregate concrete: A review. J. Clean. Prod. 2021, 295, 126435. [CrossRef]

49. Tahar, Z.-E.; Ngo, T.-T.; Kadri, E.H.; Bouvet, A.; Debieb, F.; Aggoun, S. Effect of cement and admixture on the utilization of recycled aggregates in concrete. Constr. Build. Mater. 2017, 149, 91-102. [CrossRef]

50. de Souza, A.M.; de Lima, G.E.S.; Nalon, G.H.; Lopes, M.M.S.; Júnior, A.L.D.O.; Lopes, G.J.R.; Olivier, M.J.d.A.; Pedroti, L.G.; Ribeiro, J.C.L.; de Carvalho, J.M.F. Application of the desirability function for the development of new composite eco-efficiency indicators for concrete. J. Build. Eng. 2021, 40, 102374. [CrossRef]

51. Thomas, C.; Setién, J.; Polanco, J.A.; Alaejos, P.; De Juan, M.S. Durability of recycled aggregate concrete. Constr. Build. Mater. 2013, 40, 1054-1065. [CrossRef]

52. Silva, R.; de Brito, J.; Dhir, R. Prediction of the shrinkage behavior of recycled aggregate concrete: A review. Constr. Build. Mater. 2015, 77, 327-339. [CrossRef] 